\title{
Follow-up of nonarteritic anterior ischemic optic neuropathy with optical coherence tomography angiography
}

Juejun Liu

Wuhan University

Changzheng Chen ( $\square$ whuchenchzh@163.com )

Ophthalmic Center of Renmin Hospital of Wuhan University

Li Lu

Wuhan University Renmin Hospital

\section{Zuohuizi Yi}

Wuhan University Renmin Hospital

Hongmei Zheng

Wuhan University Renmin Hospital

\section{Research article}

Keywords: Nonarteritic Anterior Ischemic Optic Neuropathy, Optical Coherence Tomography Angiography,

Capillaries Density, Follow-up

Posted Date: January 13th, 2020

DOI: https://doi.org/10.21203/rs.2.20693/v1

License: (c) (1) This work is licensed under a Creative Commons Attribution 4.0 International License. Read Full License 


\section{Abstract}

Background

To analyze the blood flow changes of radial peripapillary capillaries (RPC) and macula with time procession in patients with non-arteritic anterior ischemic optic neuropathy (NAION) using optical coherence tomography angiography (OCT-A).

Methods

A total of 21 affected eyes and 19 unaffected eyes from 21 NAION patients, and 40 eyes of 20 healthy individuals were included. Assessments of BCVA, CFP, SD-OCT, and OCT-A were performed on NAION patients at enrollment and at 1-2 weeks, 1-2 months, and 3-6 months post-enrollment. Measures of the thickness of peripapillary retinal nerve fiber layer (wRNFL) and macular ganglion cell complex (wGCC) of the whole image in SD-OCT, vessel density of RPC (WRPC) and superficial and deep vascular complexes (WSVD, WDVD) in the whole image of OCT-A, and their superior- and inferior-hemi values (s/iRNFL, s/iGCC, s/iRPC, and s/iSVD) were assessed.

Results

Compared to healthy controls, wRPC $(p<0.001)$ and WDVD $(P=0.001)$ were significantly lower in affected eyes at baseline, and there was no significant difference in wSVD $(p>0.05)$. The WRPC and wSVD values of affected eyes were significantly decreased at follow-up time points of 1-2 and 3-6 months compared to baseline $(p=0.001, p=0.000 ; p=0.000, p=0.000)$. The $s R P C$ values were significantly lower than iRPC at $1-2 / 3-$ 6 months $(p=0.001, p=0.000)$, and SSVD values were lower than iSVD at $1-2$ months $(p=0.010)$. Statistically significant correlations were found between wRPC and wRNFL values at 3-6 months $(r=0.626, p=0.022)$, between wSVD and wGCC at 1-2 weeks and 1-2 months ( $r=0.570, r=0.436 ; p=0.007, p=0.048)$.

Conclusion

OCT-A revealed a sectorial reduction in vessel density in RPC and macula with the disease progression of NAION from acute to atrophic stages, a classification associated with structural deficits.

\section{Background.}

Non-arteritic ischemic optic neuropathy (NAION) is the most common subtype of ischemic optic neuropathy occurring in middle-aged and elderly patients ${ }^{1,2}$, which might be related to transient hypoperfusion or nonperfusion of the optic nerve head $(\mathrm{ONH})^{1}$. Optical coherence tomography (OCT) has been previously used to evaluate the initial state of optic disc edema (ODE) in the course of NAION and monitor the optic nerve injury and subsequent atrophy ${ }^{3,4}$. Compared with traditional fundus angiography and doppler imaging that are used to confirm a reduction in flow to the $\mathrm{ONH}^{1,5,6}, \mathrm{OCT}-\mathrm{A}$ makes it possible to noninvasively observe and quantify the microvasculature in the optic disc and the macular retina over selected layers with depthresolved images ${ }^{7-10}$. 
Research regarding the applications of OCT-A in NAION has attracted attention over the last several years, however most of the resulting work produced small cross-sectional studies with a limited sample size focusing on post-acute NAION with resolved ODE ${ }^{9-12}$. Few studies were designed to follow up the capillary density changes of the peripapillary radial capillaries and the capillary density in the layers of the macula from acute to atrophic stages ${ }^{13}$. Measurements in previous cross-sectional studies are likely not interchangeable given that the results are from different stages of NAION with different classification criteria and blood flow parameters in variant measuring methods. This is the first study to follow up a group of patients with NAION using OCT-A. This novel technique is used here to quantitatively document the microvascular flow impairments in the peripapillary capillary of $\mathrm{ONH}$ and the macular retina over time, and to evaluate the corresponding structural deficits.

\section{Methods}

Retrospective cohort study. Patients with NAION were enrolled within 2 weeks of onset at the Eye Center of the Renmin Hospital of Wuhan University between November 2017 and June 2019. All patients received thorough ophthalmic examinations at the initial visit, including best-corrected visual acuity (BCVA) and visual field assessments, FFA (HRA2; Heidelberg Engineering, Heidelberg, Germany), color fundus photography (CFP) (Zeiss, Oberkochen, Germany; Optomap 200Tx, Optos, Marlborough, MA, USA), spectraldomain OCT (SD-OCT), and OCT-A (RTVue XR AngioVue Version 2017.1; Optovue Inc. Fremont, CA, USA) analyses. The inclusion criteria for patients with NAION are defined as ${ }^{1}$ : a complain of sudden and unilateral painless loss in visual acuity and/or visual field defect within 2 weeks; optic disc edema (ODE) associated with or without peripapillary hemorrhages at the initial visit, and the resolution of ODE during follow-up has been observed; occurrence of visual field impairment with a relative altitudinal pattern (which are usually nasal and/or inferior); segmental filling defect/delay in the optic disc during the acute stage of fluorescein fundus angiography (FFA). All patients had normal C-reactive protein blood test results, and CT and/or MRI examinations of the skull and orbit were used to exclude A-AION and other nervous system diseases affecting visual function, visual field or causing optic disc edema. Patients with evidence of any other condition that could damage the optic disc (eg. glaucoma, uveitis, optic neuritis, or diabetic retinopathy) and a history of ocular surgery were excluded. All patients were administered systemic corticosteroid therapy with oral prednisone $80 \mathrm{mg}$ for the first 2 weeks, $70 \mathrm{mg}$ for 1 week, $60 \mathrm{mg}$ for 1 week and then gradually decreased ${ }^{1,14}$. The diagnosis was confirmed by one of the investigators who are professional experts. Healthy gender- and age-matched subjects without ocular and systemic diseases (eg. diabetes and hypertension) were enrolled at a single visit with the complete examinations of indirect ophthalmoscopy, CFP, BCVA, OCT, and OCT-A. All subjects who had myopia greater than $-/+6.0$ diopters and severe cataracts that could impair the scan quality of OCT-A were excluded from this cohort. Quantitative and noninvasive assessments of BCVA, CFP, SD-OCT, and OCT-A were performed at the initial visit and repeated in patients of NAION at 1-2 weeks, 1-2 months, and 3-6 months post-enrollment. According to the literature ${ }^{1,2,4}$, the acute phase of NAION in this study was determined at the initial visit at our clinic, which was within 2 weeks of noticing visual symptoms. The follow-up intervals 1-2 weeks and 1-2 months counting from the time of enrollment generally correspond to the stage of subacute and resolution in NAION, and 3-6 months corresponds to the chronic atrophic stage. 
SD-OCT was performed in two modes including Never Fiber-ONH within a $4.9 \mathrm{~mm}$ diameter circle centered on the optic disc, and Never Fiber-GCC within a $6 \times 6 \mathrm{~mm}$ scan area centered $1 \mathrm{~mm}$ temporal to the fovea. Automatic quantitative parameters were recorded as follows: average thickness of peripapillary retinal nerve fiber layer (wRNFL, $\propto \mathrm{m})$ and macular ganglion cell complex of the whole image (wGCC, $\propto \mathrm{m}$; encompasses three layers of retinal nerve fiber layer (RNFL), ganglion cell layer (GCL) and inner-plexiform layer (IPL)), and their superior and inferior values (sRNFL, $\propto \mathrm{m}, \mathrm{iRNFL}, \propto \mathrm{m} ; \mathrm{sGCC}, \propto \mathrm{m}, \mathrm{iGCC}, \propto \mathrm{m})$.

Capillary density of radial peripapillary capillary (RPC) was measured within a $4.5 \times 4.5 \mathrm{~mm}$ scan area centered on the optic disk in the mode of Angio-Disc $4.5 \mathrm{~mm}$, and vessel density of macular retina was measured within a $3 \times 3 \mathrm{~mm}$ scan area centered on the fovea in the Angio-Retina $3.0 \mathrm{~mm}$ mode. Angio-OCT scanning was acquired using the eye tracking option. Multiple scans were performed, and images with quality score greater than or equal to 7/10 were preserved. Automatic quantitative parameters of the optic disc include average capillary density of RPC based on the whole image (wRPC, \%), and the superior- and inferior-hemi values (SRPC, \%; iRPC, \%) based on the Garway-Heath peripapillary grid (the peripapillary region is defined by two rings of $2 \mathrm{~mm}$ and $4 \mathrm{~mm}$ centered on the disc center using the deep Bruch's membrane opening as a reference for the disc margins). Segmentation of RPC was automatically selected from the internal limiting membrane (ILM) to the RNFL posterior boundary. Quantitative parameters of the macular retina include average vessel density of superficial (SVD) and deep (DVD) vascular complexes in the whole image (wSVD, \%; wDVD, \%), and the corresponding superior- and inferior-hemi values of SVD (sSVD, \%; iSVD, $\%)$. The slab of superficial retinal vascular complexes in OCT-A was automatically segmented from ILM to 10 $\propto \mathrm{m}$ above the inner plexiform layer (IPL), and the deep retinal vascular complexes were selected from $10 \propto \mathrm{m}$ above the IPL to $10 \propto \mathrm{m}$ below the outer plexiform layer (OPL).

All statistical tests were performed using SPSS version 23.0 (https://www.ibm.com/a nalytics/spssstatistics-software). Categorized data are described as frequency and percentage, and quantitative data are presented as mean and standard deviation. The Shapiro-Wilk test was used to evaluate distribution. Student's t-test and one-way analysis of variance (ANOVA) were used in cases of normal distribution, while nonparametric statistical analyses (independent samples Mann-Whitney $U$ or related-samples Wilcoxon test and Kruskal-Wallis test) were used for comparing variables between groups. Differences in proportions of gender were tested by $\chi^{2}$ test. Pearson or Spearman method was used to analyze the correlations of RPC or SVD with other parameters. A P-value $<0.05$ was considered statistically significant.

\section{Results}

A total of 21 affected eyes and 19 unaffected eyes from 21 NAION patients, and 40 eyes of 20 healthy individuals were included in this study, while 2 fellow (unaffected) eyes were excluded from the analysis due to the existing optic atrophy. In this group, 3 cases had self-reported history of hypertension and one had diabetes. 12 (57.14\%) were male and 9 (42.86\%) were female with a mean age of $54.67 \pm 7.55$ years. There was no statistical difference between healthy individuals (56.10 \pm 5.43 years) and patients with NAION in age and gender $(p=0.505, p=0.890)$. The average time after onset of symptoms at the initial visit was $5.67 \pm$ 3.06 days. Repeated measurements of OCT and OCT-A parameters were performed in 21, 21 and 13 affected eyes with NAION at follow-up intervals of 1-2 weeks, 1-2 months, and 3-6 months, respectively. Eight 
affected eyes were lost to follow-up at 3-6 months. BCVA was worse in affected eyes $(0.424 \pm 0.326$ LogMAR) than those of unaffected eyes $(0.158 \pm 0.155$ LogMAR $)$ and healthy controls $(0.097 \pm 0.085$ LogMAR) at the initial visit $(p=0.006, p=0.000)$. In affected eyes, significant improvement of BCVA was found at the last follow-up visit $(0.357 \pm 0.326$ LogMAR $)$ compared to the initial assessment $(p=0.021)$.

Comparison of OCT and OCT-A parameters in ONH. At the initial visit, wRNFL values in affected eyes were significantly higher ( $p<0.001$ for both), while wRPC values were lower in affected eyes ( $<<0.001$ for both) (Table 1) compared to unaffected eyes and healthy control eyes. Comparison within affected eyes of NAION: the overall differences of WRNFL and WRPC at the four intervals were statistically significant (Pख0.05) (Table 2, Fig. 1). Post Hoc multiple comparisons showed a significant difference of wRPC values between intervals of baseline and 1-2/3-6 months, between $1-2$ weeks and $3-6$ months post-enrollment $(p=0.001$, $p=0.000, p=0.001)$, accompanied by significant differences between SRPC and iRPC observed at 1-2 months and 3-6 months follow-ups $(p=0.001, p=0.000$ ) (Table 2, Fig. 1$)$. And similar changes has been found in wRNFL values (Table 2, Fig. 1).

Table 1

Comparison of OCT and OCTA parameters at initial visit among affected and unaffected eyes of NAION patients, and healthy controls.

\begin{tabular}{|c|c|c|c|c|c|}
\hline & \multicolumn{2}{|l|}{ ONH $(\chi \pm s)$} & \multicolumn{3}{|c|}{ Macula ( $\chi \pm s)$} \\
\hline & wRNFL $(\propto m)$ & wRPC(\%) & $w G C C(\propto m)$ & wSVD(\%) & wDVD(\%) \\
\hline Nor $(n=40)$ & $111.60 \pm 6.62$ & $\begin{array}{l}50.47 \pm \\
1.71\end{array}$ & $\begin{array}{l}105.74 \pm \\
6.86\end{array}$ & $\begin{array}{l}45.98 \pm \\
2.74\end{array}$ & $\begin{array}{l}49.08 \pm \\
3.19\end{array}$ \\
\hline $\begin{array}{l}\text { Unaffected }(n= \\
\text { 19) }\end{array}$ & $\begin{array}{l}113.84 \pm \\
13.16\end{array}$ & $\begin{array}{l}50.74 \pm \\
2.00\end{array}$ & $\begin{array}{l}106.68 \pm \\
7.61\end{array}$ & $\begin{array}{l}45.49 \pm \\
1.97\end{array}$ & $\begin{array}{l}47.60 \pm \\
3.20\end{array}$ \\
\hline Affected $(n=21)$ & $\begin{array}{l}179.24 \pm \\
17.77\end{array}$ & $\begin{array}{l}46.32 \pm \\
2.63\end{array}$ & $\begin{array}{l}103.67 \pm \\
6.95\end{array}$ & $\begin{array}{l}46.07 \pm \\
2.09\end{array}$ & $\begin{array}{l}45.82 \pm \\
2.96\end{array}$ \\
\hline $\mathrm{P}^{\mathrm{a}}$ value & $0.000^{\star}$ & $0.000^{*}$ & 0.215 & 0.838 & $0.001^{*}$ \\
\hline $\mathrm{P}^{\mathrm{b}}$ value & 0.638 & 0.570 & 0.649 & 0.197 & 0.057 \\
\hline $\mathrm{P}^{\mathrm{c}}$ value & $0.000^{*}$ & $0.000^{*}$ & 0.304 & 0.444 & 0.121 \\
\hline \multicolumn{6}{|c|}{$\begin{array}{l}\text { NAION, non-arteritic anterior ischemic optic neuropathy. ONH, optical never head. WRNFL }(\alpha \mathrm{m}) \text {, average } \\
\text { thickness of peripapillary retinal nerve fiber layer. WGCC }(\propto \mathrm{m}) \text {, average ganglion cell complex thickness. } \\
\text { WRPC(\%), average capillary density of radial peripapillary capillary. WSVD }(\%) \text {, average superficial vessel } \\
\text { density. WDVD(\%), average deep vessel density. }\end{array}$} \\
\hline \multicolumn{6}{|c|}{$\begin{array}{l}P^{a} \text {, } p \text {-values for normal controls versus affected eyes evaluated by Mann-Whitney } U \text { test. } P^{b}, p \text {-values fo } \\
\text { healthy subjects versus unaffected eyes using Mann-Whitney } U \text { test. } P^{c}, p \text {-values for affected subjects } \\
\text { versus unaffected eyes using Wilcoxon test. *, P-value< } 0.05 \text { was considered statistically significant. }\end{array}$} \\
\hline
\end{tabular}


Table 2

OCT and OCTA parameters in ONH in affected eyes of NAION

\begin{tabular}{|c|c|c|c|c|c|c|c|c|}
\hline & \multicolumn{3}{|c|}{$\operatorname{RNFL}(\alpha \mathrm{m})(\chi \pm \mathrm{s})$} & \multirow{2}{*}{$\begin{array}{l}P^{s i} \\
\text { value }\end{array}$} & \multicolumn{3}{|c|}{$\operatorname{RPC}(\%)(\chi \pm s)$} & \multirow{2}{*}{$\begin{array}{l}\mathrm{P}^{s i} \\
\text { value }\end{array}$} \\
\hline & wRNFL & sRNFL & iRNFL & & wRPC & sRPC & iRPC & \\
\hline $\begin{array}{l}\text { baseline(n } \\
=21)\end{array}$ & $\begin{array}{l}179.24 \pm \\
17.77\end{array}$ & $\begin{array}{l}186.95 \pm \\
23.18\end{array}$ & $\begin{array}{l}171.67 \pm \\
19.78\end{array}$ & $0.019^{*}$ & $\begin{array}{l}46.32 \pm \\
2.63\end{array}$ & $\begin{array}{l}46.90 \pm \\
3.69\end{array}$ & $\begin{array}{l}48.29 \pm \\
5.55\end{array}$ & 0.266 \\
\hline $\begin{array}{l}1 \sim 2 \mathrm{w}(\mathrm{n} \\
=21)\end{array}$ & $\begin{array}{l}153.72 \pm \\
25.19\end{array}$ & $\begin{array}{l}156.29 \pm \\
31.19\end{array}$ & $\begin{array}{l}150.29 \pm \\
26.53\end{array}$ & 0.140 & $\begin{array}{l}44.29 \pm \\
3.28\end{array}$ & $\begin{array}{l}44.29 \pm \\
4.70\end{array}$ & $\begin{array}{l}46.75 \pm \\
5.42\end{array}$ & $0.035^{\star}$ \\
\hline $\begin{array}{l}1 \sim 2 \mathrm{~m}(\mathrm{n} \\
=21)\end{array}$ & $\begin{array}{l}111.90 \pm \\
11.14\end{array}$ & $\begin{array}{l}104.29 \pm \\
15.73\end{array}$ & $\begin{array}{l}119.52 \pm \\
18.39\end{array}$ & $0.013^{*}$ & $\begin{array}{l}41.45 \pm \\
3.43\end{array}$ & $\begin{array}{l}40.81 \pm \\
4.13\end{array}$ & $\begin{array}{l}44.61 \pm \\
5.55\end{array}$ & $0.016^{*}$ \\
\hline $\begin{array}{l}3 \sim 6 \mathrm{~m}(\mathrm{n} \\
=13)\end{array}$ & $\begin{array}{l}83.00 \pm \\
14.35\end{array}$ & $\begin{array}{l}74.23 \pm \\
10.35\end{array}$ & $\begin{array}{l}91.85 \pm \\
22.28\end{array}$ & $0.007^{*}$ & $\begin{array}{l}38.22 \pm \\
4.00\end{array}$ & $\begin{array}{l}36.53 \pm \\
6.19\end{array}$ & $\begin{array}{l}42.75 \pm \\
6.60\end{array}$ & $0.013^{*}$ \\
\hline$P$ value & $0.000^{\star}$ & $0.000^{*}$ & $0.000^{*}$ & - & $0.000^{\star}$ & $0.000^{*}$ & $0.029^{*}$ & - \\
\hline \multicolumn{9}{|c|}{$\begin{array}{l}\text { s/iRNFL }(\propto m) \text {, superior- and inferior-hemi thickness of peripapillary retinal nerve fiber layer. } s / \mathrm{iRPC}(\%) \text {, } \\
\text { superior- and inferior-hemi capillary density of radial peripapillary capillary. }\end{array}$} \\
\hline
\end{tabular}

Comparison of OCT and OCT-A parameters in macular retina. At the initial visit, there was no significant difference of wGCC and wSVD among the three groups ( $p>0.05$ for all), however WDVD was significantly lower in affected eyes compared with healthy controls $(p=0.001)$ (Table 1). Comparisons within affected eyes of NAION: the overall differences of WGCC and WSVD at four intervals were statistically significant

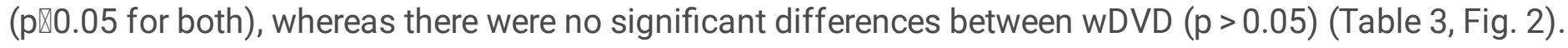
Post Hoc multiple comparisons showed significant differences in wSVD values between the initial visit and 1-2/3-6 months, between 1-2 weeks and 3-6 months follow-ups $(p=0.000, p=0.000, p=0.000)$, accompanied by significant differences between SSVD and iSVD observed at the 1-2 months follow-up ( $p=$ 0.010) (Table 3, Fig. 2). And similar changes has been found in wGCC values (Table 3, Fig. 2). 
Table 3

OCT and OCTA parameters in macular retina in affected eyes of NAION

\begin{tabular}{|c|c|c|c|c|c|c|c|c|c|}
\hline & \multicolumn{3}{|c|}{$\operatorname{GCC}(\propto m)\left(\chi^{ \pm s}\right)$} & \multirow{2}{*}{$\begin{array}{l}\mathrm{P}^{s i} \\
\text { value }\end{array}$} & \multicolumn{3}{|c|}{$\operatorname{sVD}(\%)(\chi \pm s)$} & \multirow{2}{*}{$\begin{array}{l}\mathrm{P}^{\mathrm{si}} \\
\text { value }\end{array}$} & \multirow[t]{2}{*}{ wDVD(\%) } \\
\hline & wGCC & sGCC & iGCC & & wSVD & SSVD & iSVD & & \\
\hline $\begin{array}{l}\text { baseline(n } \\
=21)\end{array}$ & $\begin{array}{l}103.67 \\
\pm 6.95\end{array}$ & $\begin{array}{l}102.67 \\
\pm 7.91\end{array}$ & $\begin{array}{l}104.62 \\
\pm 7.34\end{array}$ & 0.114 & $\begin{array}{l}46.07 \\
\pm 2.09\end{array}$ & $\begin{array}{l}46.19 \\
\pm 2.16\end{array}$ & $\begin{array}{l}45.89 \\
\pm 2.30\end{array}$ & 0.149 & $\begin{array}{l}45.82 \pm \\
2.96\end{array}$ \\
\hline $\begin{array}{l}1 \sim 2 \mathrm{w}(\mathrm{n} \\
=21)\end{array}$ & $\begin{array}{l}99.48 \\
\pm 7.69\end{array}$ & $\begin{array}{l}95.52 \\
\pm 8.80\end{array}$ & $\begin{array}{l}103.48 \\
\pm 8.80\end{array}$ & $0.001^{*}$ & $\begin{array}{l}43.70 \\
\pm 2.39\end{array}$ & $\begin{array}{l}43.91 \\
\pm 2.43\end{array}$ & $\begin{array}{l}43.63 \\
\pm 2.73\end{array}$ & 0.626 & $\begin{array}{l}46.43 \pm \\
3.38\end{array}$ \\
\hline $\begin{array}{l}1 \sim 2 \mathrm{~m}(\mathrm{n} \\
=21)\end{array}$ & $\begin{array}{l}89.24 \\
\pm 6.66\end{array}$ & $\begin{array}{l}84.62 \\
\pm 7.72\end{array}$ & $\begin{array}{l}93.85 \\
\pm 7.72\end{array}$ & $0.000^{*}$ & $\begin{array}{l}41.10 \\
\pm 2.63\end{array}$ & $\begin{array}{l}40.32 \\
\pm 3.12\end{array}$ & $\begin{array}{l}41.75 \\
\pm 2.47\end{array}$ & $0.010^{*}$ & $\begin{array}{l}46.99 \pm \\
2.39\end{array}$ \\
\hline $\begin{array}{l}3 \sim 6 \mathrm{~m}(\mathrm{n} \\
=13)\end{array}$ & $\begin{array}{l}80.62 \\
\pm 8.62\end{array}$ & $\begin{array}{l}74.62 \\
\pm 9.46\end{array}$ & $\begin{array}{l}86.54 \\
\pm 10.37\end{array}$ & $0.002^{*}$ & $\begin{array}{l}37.16 \\
\pm 3.77\end{array}$ & $\begin{array}{l}36.92 \\
\pm 3.89\end{array}$ & $\begin{array}{l}36.88 \\
\pm 4.06\end{array}$ & 0.807 & $\begin{array}{l}47.44 \pm \\
3.35\end{array}$ \\
\hline$P$ value & $0.000^{*}$ & $0.000^{*}$ & $0.000^{*}$ & - & $0.000^{*}$ & $0.000^{*}$ & $0.000^{*}$ & - & 0.075 \\
\hline
\end{tabular}

Spearman's coefficients indicated significant relationships between WRPC and wRNFL at 3-6 months followups $(r=0.626, p=0.022)$, between wSVD and wGCC at $1-2$ weeks and $1-2$ months follow ups $(r=0.570, r=$ $0.436 ; p=0.007, p=0.048)$, and between wRNFL and wGCC at 1-2 months and 3-6 months follow ups ( $r=$ $0.615, r=0.621 ; p=0.003, p=0.024)$. No correlation of wRPC/SVD/DVD with age was found in healthy controls $(p>0.05$ for all).

\section{Discussion}

Most cross-sectional studies to date addressing the atrophic stage ( $>3$ months) of NAION have reported a consistent conclusion of significant reduction of peripapillary radial capillaries (RPC) and ${ }^{9,12,15}$ capillaries in macular retina using OCT-A 9,16 . Also, these OCT-A derived capillary density changes in RPC were spatially correlated with the severity of visual field defect and thinning of peripapillary RNFL ${ }^{9,15}$. Thus, it has been well accepted that there is an obligatory loss of capillary density resulting from the loss of corresponding layers of neural tissue in the pathological progression of NAION 9,12,15,16. A few studies concerning OCT-A in the acute stage of NAION show the defects in peripapillary microcirculation ${ }^{13,17,18}$. Song et al. ${ }^{19}$ and Rebolleda et,al. ${ }^{13}$ have reported that there were no significant differences of reduced peripapillary vessel density in acute and chronic stages. However, they assessed the measurements with smaller scanning area ${ }^{13}$, and compared the acute and chronic stages with the division of 21 days using two separate patient pools ${ }^{19}$, which may generally correspond to the comparison between 1-2 weeks and 1-2 months follow-up intervals in our cohort that correspond to the stage of resolution. In this cohort, in addition to the significant reduction of WRPC at enrollment compared to unaffected eyes and healthy controls, we also fund that WRPC in NAION- 
affected eyes decreased significantly from the acute stage to the stages of resolution and atrophy, along with a more drastic reduction of SRPC, suggesting a sectoral reduction of RPC as the ODE subsided.

The most plausible explanation for an apparent decrease in RPC density during the acute phase could be the mechanical compression and impedance of the flow in RPC from the edema of the optic nerve ${ }^{13,17}$, and the local attenuated signal strength caused by the edema of the tissue and penetration of coherent light may also contribute a decrease in capillary density ${ }^{17}$. In addition, it is possible that some patients are already beginning to show loss of axons in the setting of edema and axoplasmic flow of the remaining axons and that the reduced capillary density result from axon loss which would be masked by the edema ${ }^{1,4}$.

Compared to peripapillary RNFL thinning, the pattern of GCL/GCC thinning may reflect earlier structural changes caused by ischaemia of the optic nerve in NAION ${ }^{20,21}$. Thinning of inner layers in macula could be detected within one week after the ischaemic event ${ }^{20,21}$ reflecting the early damage of RGC and the axons ${ }^{3,20-23}$, and peak at 3-6 months and last for $6-12$ months $^{3,22,23}$. Our results showed that wGCC and the corresponding WSVD in affected eyes were gradually decreased at 1-2 weeks follow-ups, and aggravated at 1-2 and 3-6 months follow-ups along with worsening superior hemifield defect. At the stage of resolution, we found a significant correlation between the reduction of WSVD and WGCC, which has not been detected in previous reports. Together with the significant association between wGCC thinning and wRNFL, our results provide further data to support the hypothesis that thinning of GCL in macula was secondary to the degeneration of peripapillary axons that are prone to suffer from hypoxia and ischmia ${ }^{20,23,24}$. There could be a vicious cycle about the neural-vascular interactions in the pathological progression of $\mathrm{NAION}^{1,24}$.

Although some patients showed mild reduction in WGCC and WSVD at the enrollment (average duration of onset was $5.67 \pm 3.06$ days), the overall difference among three groups was not significant enough to draw a confirmed conclusion. While, at the acute stage of NAION, the edema of RNFL in macula would mask the ability to detect significant thinning of the underlying layers of GCL and IPL ${ }^{23}$ and this may also explain that the correlation between WSVD and WGCC particularly occurred at the stage of resolution. However, the OCT-A derived capillary density in SVD was expected to show decrease due to both the edema of RNFL and/or early thinning of the underlying layers ${ }^{23,25}$, it might be that, as Augstburger et, al. ${ }^{9}$ proposed, the decrease of SVD in the $6 \times 6 \mathrm{~mm}$ scan of OCT-A predominates near the large retinal vessels of the arcades and less at the parafoveal areas where the capillary network converges and forms an anastomotic ring ${ }^{9,24,25}$. And the axonal swelling or RNFL edema resulting from the blocked axoplasm and leading to impedance in flow of RPC and retinal vessels might be severer in the site closer to the optic disc. While, Fard et al. ${ }^{26}$ have reported an early reduction of SVD and DVD in $6 \times 6 \mathrm{~mm}$ scans but not of GCC at the acute stage within 2 weeks of onset. It might be that we missed the changes outside $3 \times 3 \mathrm{~mm}$ scanning area in the early stage. And it is possible that oral corticosteroid therapy accelerates the regression of $\mathrm{ODE}^{14}$ and therefore makes the early reduction of SVD insignificant. Besides, an early reduction of WDVD has been detected in our study. It might be explained that the deep capillary vortexes ${ }^{27}$ might be earlier or more frequently to compensate for the lower blood flow and the changes of hypoxia and ischemia in macula as previously reported in patients with hypertension and diabetes mellitus ${ }^{28,29}$. 
Contrary to previous results of decreased DVD in chronic stage with macular $6 \times 6 \mathrm{~mm}$ OCT-A imaging 9,16 , our results with $3 \times 3 \mathrm{~mm}$ scan show that the WDVD did not decrease significantly with time procession. This could be explained by the enhanced visibility of deep retinal complexes resulted from severer thinning of inner layers. Although grading accuracy for $3 \times 3 \mathrm{~mm}$ scans was significantly higher than for $6 \times 6 \mathrm{~mm}$ scans which has limited vascular depth discrimination and is prone to induce overestimation of the measurements and mix DVD with the SVD changes ${ }^{25,30}$, the limited $3 \times 3 \mathrm{~mm}$ scanning area of OCT-A could miss those changes outside the confined area and therefore underestimate the results.

There are several limitations in our study, including its retrospective nature, the small number of subjects, and some loss to follow-up at 3-6 months. Here, we focused on flow alterations with time, yet visual field loss of threshold was not analyzed in detail as previous studies showed a corresponding loss of structure and capillary density in the location of the visual field loss9,13,26. Additionally, vasculature in prelaminar and laminar slabs was not evaluated due to the current limits of the technology, which may be more related to the ischemia mechanism of PCA.

\section{Conclusions.}

This study is the first to follow up a cohort of patients with NAION and analyze the microvascular flow impairment in RPC and the macular retina from acute to atrophic stages using consistent devices of OCT and OCT-A. We provide further evidence to support that there is a sectorial reduction of vessel density in RPC and macula with the disease progression of NAION from acute to atrophic stages, a classification associated with structural deficits.

\section{Abbreviations}

OCT-A

optical coherence tomography angiography

NAION

nonarteritic anterior ischemic optic neuropathy

RPC

radial peripapillary capillaries

RNFL

peripapillary retinal nerve fiber layer

GCC

ganglion cell complex

GCL

ganglion cell layer

IPL

inner-plexiform layer

S/DVD

vessel density of superficial and deep vascular complexes

$\mathrm{ONH}$ 
optic nerve head

ODE

optic disc edema

PCA

posterior ciliary artery

CFP

color fundus photography

\section{Declarations}

\section{Ethics approval and consent to participate.}

This retrospective study was approved by the Renmin Hospital of Wuhan University and was conducted in compliance with the Declaration of Helsinki.

\section{Consent for publication.}

Not applicable.

\section{Availability of data and material.}

The datasets used and/or analyzed during the current study are available from the corresponding author on reasonable request. All participants provided their written informed consent to participate in the study.

\section{Competing interests.}

Not applicable.

\section{Funding.}

Not applicable.

\section{Authors' contributions.}

$\mathrm{JJ}$ and L contributed to patient care and literature search. All authors, including JJ, CZ, L, ZHZ, and HM contributed to data collection, data analysis, and data interpretation. JJ, and CZ contributed to writing the manuscript. All authors have read and approved the final manuscript.

\section{Acknowledgements.}

We want to especially express our gratitude to professor CZ and HM for their help on collecting data and support our work.

\section{References}

1. Hayreh SS. Ischemic optic neuropathy. Prog Retin Eye Res. 2009;28(1):34-62. 
2. Hayreh SS, Zimmerman MB. Nonarteritic anterior ischemic optic neuropathy: natural history of visual outcome. Ophthalmology. 2008;115(2):298-305 e292.

3. Goto K, Miki A, Araki S, et al. Time Course of Macular and Peripapillary Inner Retinal Thickness in Nonarteritic Anterior Ischaemic Optic Neuropathy Using Spectral-Domain Optical Coherence Tomography. Neuro-Ophthalmology. 2016;40(2):74-85.

4. Contreras I, Noval S, Rebolleda G, Munoz-Negrete FJ. Follow-up of nonarteritic anterior ischemic optic neuropathy with optical coherence tomography. Ophthalmology. 2007;114(12):2338-2344.

5. Oto S, Yilmaz G, Cakmakci S, Aydin P. Indocyanine green and fluorescein angiography in nonarteritic anterior ischemic optic neuropathy. Retina. 2002;22(2):187-191.

6. Kuerten D, Fuest M, Bienert M, Plange N. Retrobulbar and intraocular blood flow in anterior ischaemic optic neuropathy are linked to the functional impairment. Int Ophthalmol. 2019;39(3):597-604.

7. Kashani AH, Chen CL, Gahm JK, et al. Optical coherence tomography angiography: A comprehensive review of current methods and clinical applications. Prog Retin Eye Res. 2017;60:66-100.

8. Ghasemi Falavarjani K, Tian JJ, Akil H, Garcia GA, Sadda SR, Sadun AA. Swept-Source Optical Coherence Tomography Angiography of the Optic Disk in Optic Neuropathy. Retina. 2016;36 Suppl $1: S 168-S 177$.

9. Augstburger E, Zeboulon P, Keilani C, Baudouin C, Labbe A. Retinal and Choroidal Microvasculature in Nonarteritic Anterior Ischemic Optic Neuropathy: An Optical Coherence Tomography Angiography Study. Invest Ophthalmol Vis Sci. 2018;59(2):870-877.

10. Wylegala A. Principles of OCTA and Applications in Clinical Neurology. Curr Neurol Neurosci Rep. 2018;18(12):96.

11. Chun-Hsiu. L, Wei-Chi. W, Ming-Hui. S, Ling-Yuh. K. Comparison of the Retinal Microvascular Density Between Open Angle Glaucoma and Nonarteritic Anterior Ischemic Optic Neuropathy. Invest Ophthalmol Vis Sci. 2017;58:3350-3356.

12. Liu CH, Kao LY, Sun MH, Wu WC, Chen HS. Retinal Vessel Density in Optical Coherence Tomography Angiography in Optic Atrophy after Nonarteritic Anterior Ischemic Optic Neuropathy. J Ophthalmol. 2017;2017:9632647.

13. Rebolleda G, Diez-Alvarez L, Garcia Marin Y, de Juan V, Munoz-Negrete FJ. Reduction of Peripapillary Vessel Density by Optical Coherence Tomography Angiography from the Acute to the Atrophic Stage in Non-Arteritic Anterior Ischaemic Optic Neuropathy. Ophthalmologica. 2018;240(4):191-199.

14. Hayreh SS, Zimmerman MB. Non-arteritic anterior ischemic optic neuropathy: role of systemic corticosteroid therapy. Graef Arch Clin Exp. 2008;246(7):1029-1046.

15. Hata M, Oishi A, Muraoka Y, et al. Structural and Functional Analyses in Nonarteritic Anterior Ischemic Optic Neuropathy: Optical Coherence Tomography Angiography Study. J Neuro-Ophthalmol. 2017;37(2):140-148.

16. Wang H, Meng ZY, Li SG, Wang JJ, Sun J, Li HY. Macular evaluation of the retinal and choroidal vasculature changes in anterior ischemic optic neuropathy-a case control study. BMC Ophthalmol. 2018;18(1):341. 
17. Sharma S, Ang M, Najjar RP, et al. Optical coherence tomography angiography in acute non-arteritic anterior ischaemic optic neuropathy. Br J Ophthalmol. 2017;101(8):1045-1051.

18. Rougier MB, Delyfer MN, Korobelnik JF. OCT angiography of acute non-arteritic anterior ischemic optic neuropathy. J Fr Ophtalmol. 2017;40(2):102-109.

19. Song Y, Min JY, Mao L, Gong YY. Microvasculature dropout detected by the optical coherence tomography angiography in nonarteritic anterior ischemic optic neuropathy. Lasers Surg Med. 2018;50(3):194-201.

20. Akbari M, Abdi P, Fard MA, et al. Retinal Ganglion Cell Loss Precedes Retinal Nerve Fiber Thinning in Nonarteritic Anterior Ischemic Optic Neuropathy. J Neuroophthalmol. 2016;36(2):141-146.

21. De Dompablo E, Garcia-Montesinos J, Munoz-Negrete FJ, Rebolleda G. Ganglion cell analysis at acute episode of nonarteritic anterior ischemic optic neuropathy to predict irreversible damage. A prospective study. Graef Arch Clin Exp. 2016;254(9):1793-1800.

22. Aggarwal D, Tan O, Huang D, Sadun AA. Patterns of ganglion cell complex and nerve fiber layer loss in nonarteritic ischemic optic neuropathy by Fourier-domain optical coherence tomography. Invest Ophthalmol Vis Sci. 2012;53(8):4539-4545.

23. Larrea BA, Iztueta MG, Indart LM, Alday NM. Early axonal damage detection by ganglion cell complex analysis with optical coherence tomography in nonarteritic anterior ischaemic optic neuropathy. Graefes Arch Clin Exp Ophthalmol. 2014;252(11):1839-1846.

24. Selvam S, Kumar T, Fruttiger M. Retinal vasculature development in health and disease. Prog Retin Eye Res. 2018;63:1-19.

25. Campbell JP, Zhang M, Hwang TS, et al. Detailed Vascular Anatomy of the Human Retina by ProjectionResolved Optical Coherence Tomography Angiography. Sci Rep. 2017;7:42201.

26. Fard MA, Ghahvechian H, Sahrayan A, Subramanian PS. Early Macular Vessel Density Loss in Acute Ischemic Optic Neuropathy Compared to Papilledema: Implications for Pathogenesis. Trans/ Vis Sci Technol. 2018;7(5):10.

27. Bonnin S, Mane V, Couturier A, et al. New Insight into the Macular Deep Vascular Plexus Imaged by Optical Coherence Tomography Angiography. Retina-J Ret Vit Dis. 2015;35(11):2347-2352.

28. Chen Q, Ma QK, Wu CM, et al. Macular Vascular Fractal Dimension in the Deep Capillary Layer as an Early Indicator of Microvascular Loss for Retinopathy in Type 2 Diabetic Patients. Invest Ophth Vis Sci. 2017;58(9):3785-3794.

29. Lim HB, Lee MW, Park JH, Kim KM, Jo YJ, Kim JY. Changes in Ganglion Cell-Inner Plexiform Layer Thickness and Retinal Microvasculature in Hypertension: An OCT Angiography Study. Am J Ophthalmol. 2018.

30. Xu X, Yannuzzi NA, Fernandez-Avellaneda P, et al. Differentiating veins from arteries on optical coherence tomography angiography by identifying deep capillary plexus vortices. Am J Ophthalmol. 2019.

31. Rebolleda G, Diez-Alvarez L, de Dompablo E, Munoz-Negrete FJ. Early Macular Vessel Density Loss in Acute Ischemic Optic Neuropathy Compared to Papilledema: Implications for Pathogenesis. Trans/ Vis Sci Techn. 2019;8(1). 


\section{Figures}

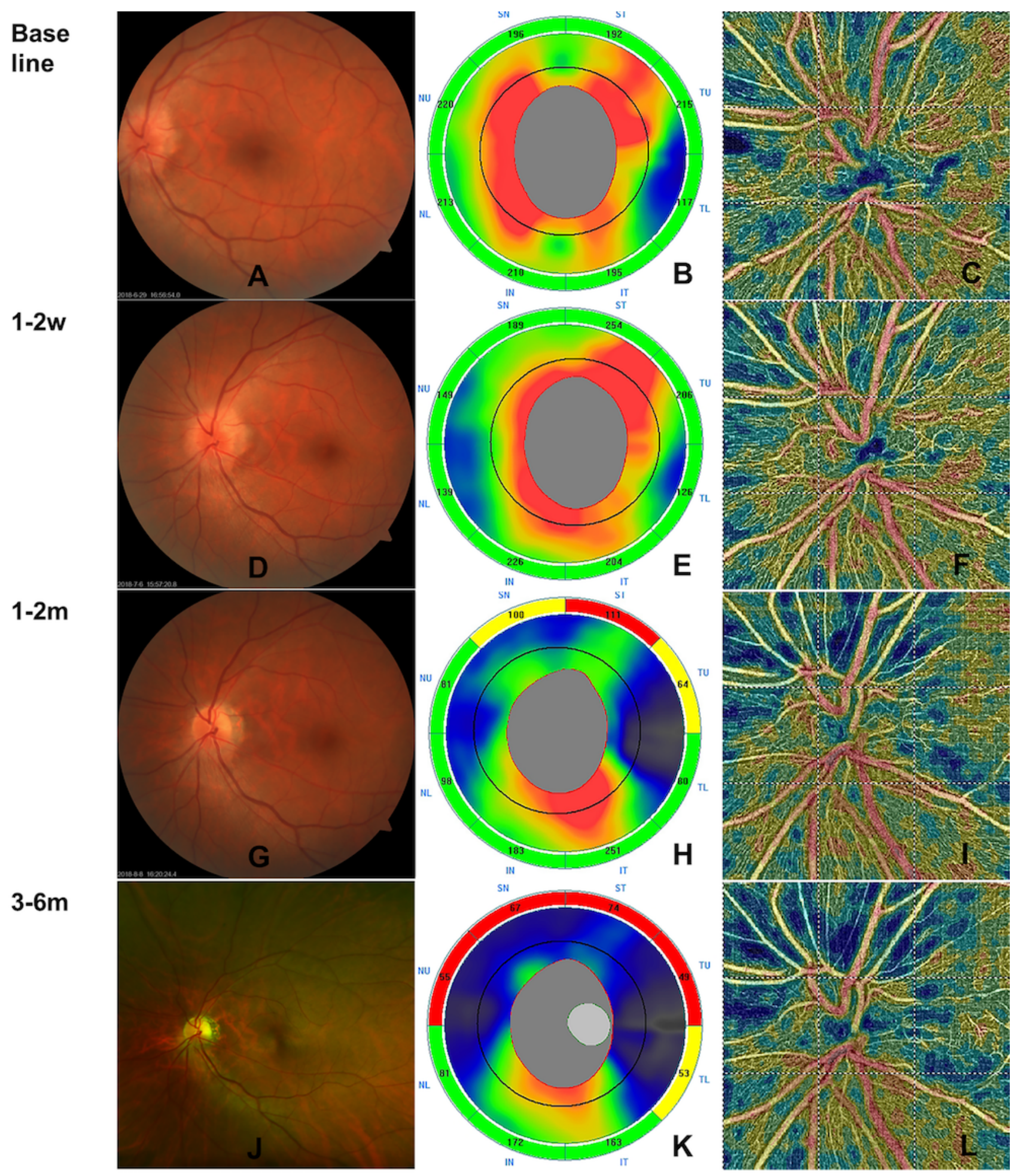

\section{Figure 1}

The time course of CFP, structural OCT and Angio-OCT (OCT-A) findings in ONH in a case with NAION (baseline: A C, 1 2 w: D F, 1 2 m: G I, 3 6 m: J L). At presentation, CFP indicated the occurrence of ODE at the initial visit $(A)$, and the subsequent resolution $(D, G)$ of ODE and the final pallor of optic disc $(J)$. Thinning of wRNFL at 1 2 $\mathrm{m}(\mathrm{H})$ and 3 6 $\mathrm{m}(\mathrm{K})$ was lower than that at initial visit (B) and 1 2 $\mathrm{w}$ follow-up 
(E) as the increasing areas of red or yellow color shown in the map, along with a worsening superior hemifield defect (Table 2). The reduction of wRPC was lower at 1 2 $\mathrm{m}$ (I) and 3 6 $\mathrm{m}$ (L) follow-ups compared with the initial visit (C) and 1 2 w (F) as the increasing areas of blue color shown in the map (Table 2). CFP, color fundus photography. ONH, optical never head. NAION, non-arteritic anterior ischaemic optic neuropathy. ODE, optic disc edema. wRNFL, average thickness of peripapillary retinal nerve fiber layer. WRPC, average vessel density of radial peripapillary capillary in the whole image of OCT-A.

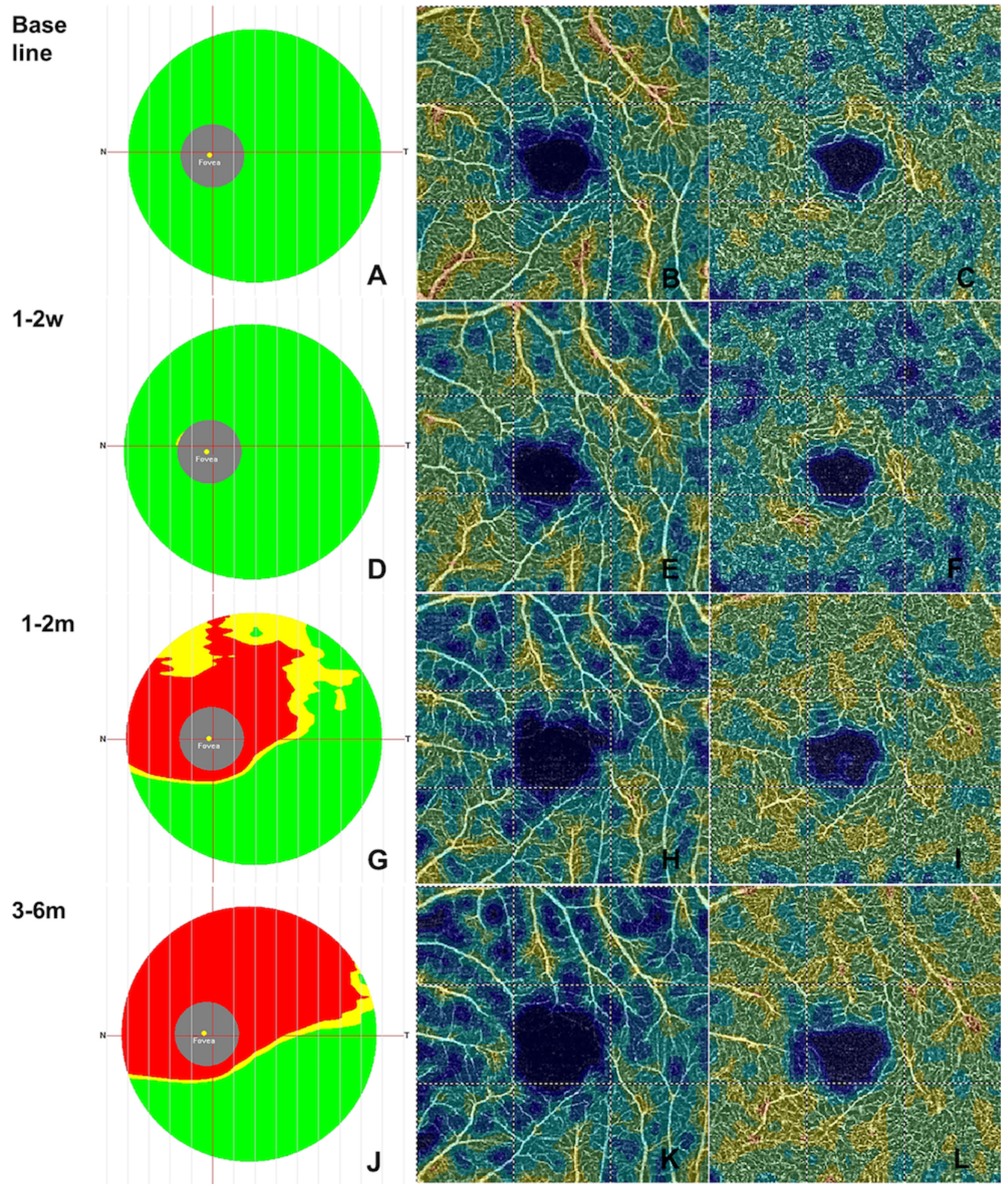

Figure 2 
The time course of structural OCT and Angio-OCT findings in macular retina in the same patient in Fig. 1 (baseline: $A \sim C, 1 \sim 2 \mathrm{w}: \mathrm{D} \sim \mathrm{F}, 1 \sim 2 \mathrm{~m}: \mathrm{G} \sim \mathrm{I}, 3 \sim 6 \mathrm{~m}$ : J L). Thinning of wGCC at 1 2 $\mathrm{m}(\mathrm{G})$ and $3 \sim 6 \mathrm{~m}(\mathrm{~J})$ was lower than that at initial visit (A) and 1 2 $\mathrm{w}$ follow-up (D) as the increasing areas of red or yellow color shown in the map, along with a worsening superior hemifield defect (Table 3 ). The reduction of WSVD was lower at 1 2 $\mathrm{m}(\mathrm{H})$ and 3 6 $\mathrm{m}(\mathrm{K})$ follow-ups compared with the initial visit (B) and 1 2 $\mathrm{w}(\mathrm{E})$ as the increasing areas of blue color shown in the map, while WDVD was gradually increased over time $(C, F, I, L)$ (Table 3). wGCC, average ganglion cell complex thickness; wSVD, average superficial vessel density; wDVD, average deep vessel density in the whole image of OCT-A. 